\title{
Typical and Individual Doctoral Processes and Lifecourses: The Types of Narratives of the Project Manager, the Survivor and the Seeker
}

\author{
Minna Maunula ${ }^{1, *}$ \\ ${ }^{1}$ University of Jyvaskyla, Kokkola University Consortium Chydenius, Kokkola, Finland \\ *Correspondence: University of Jyvaskyla, Kokkola University Consortium Chydenius, P.O. Box 567, FI-67701 \\ Kokkola, Finland. Tel: 358-40-805-4424. E-mail: minna.maunula@chydenius.fi
}

Received: May 24, 2015

Accepted: June 18, $2015 \quad$ Online Published: July 20, 2015

doi:10.5430/wje.v5n4p38

URL: http://dx.doi.org/10.5430/wje.v5n4p38

\begin{abstract}
One task of the doctoral education is, globally as well as nationally, to produce and renew the highest expertise and knowledge in a high quality and efficient way. Even though in this global time the high-quality knowledge and skills are a competition factor which the success of the societies is expected to be able to lean on, also the doctoral students and their individual factors are significant. The accelerating global change is strongly reflected at the individual level: an attempt is made to respond to the changing expectations and to prepare individually and diversely. The individual doctoral students and the graduating doctors come from different everyday lives and contexts. The graduating doctors' expertise and skills are individually colored during the individual doctoral processes. Often the doctoral students' and the graduating doctors' individuality is ignored - even though individuality in other contexts is identified more clearly than before. In this article I examine the lifecourse experiences and stories of under-40-year-old female doctoral students with a family and form three different types of doctoral student on the basis of the material. The examination concentrates on the areas of the lifecourse; the family, doctoral studies and work as well as on the dynamic wholeness formed by them in the temporal continuum of the lifecourse. The objective is to make the generalized doctoral process more comprehensively intelligible.
\end{abstract}

Keywords: Lifecourse, Doctoral Studies, Doctoral Student, Individual, Type of Narrative

\section{Introduction}

\subsection{Doctoral Studies as A Part of the Lifecourse}

Doctoral studies have a significant role in the lifecourse of a doctoral student, the doctoral process is reflected both in the everyday life and in the future in many ways (McAlpine \& Mitra, 2015). Doctoral studies overlap with the individual lifecourse at the micro level at the same time becoming a part of the social development of the macro level (McAlpine \& Norton, 2006). The joint observation of discourse of the micro and macro level of the lifecourse makes concrete the intersection of the major lines and the everyday life.

The experiences of the doctoral studies as a part of the lifecourse consist of different starting points, of everyday lives and the expectations for the future. The individual lives and their examination make the social change and the change which is manifested at the individual level seen and understandable (Diewald \& Mayer, 2009) such as the comprehensive change in the family life, doctoral studies and working life.

The pedagogical-sociological concept of lifecourse represents the process of both the micro and the macro level: social relations of the individual in a changing society (Levinson, 1978; 1996). In the examination, the comprehensiveness instead of one sector of lifecourse and the development during the whole lifecourse with its multiple factors are emphasized. The significant events of the lifecourse form a continuum and a dynamic wholeness. (Mayer, 2009; Beck \& Beck-Gernsheim, 2002.) As concepts, lifecourse, lifespan and biography have converged with the individualizing development, their fluent team-play helps to understand the reflective and construed nature of the individual lifecourse as a part of the social change. (Diewald \& Mayer, 2009.)

The concept of the lifecourse as narrative contains the interaction between individuality and communality of life, the process-like nature and temporality. In other words, in an individual lifecourse the family, doctoral studies and work are told as part of one's own biography, to the continuing and logically proceeding wholeness of its wide context. 
(Chase, 2005).

During their lifecourse, the present doctoral students have experienced numerous intertwinings and changes at the macro and micro levels which reflect constant modernization and individualization development (May, 2011). The individual lifecourses contain even fewer processes and stages which are uniform to everybody, the linearity decreases and cyclical nature increases. (Macmillan, 2005; Tammelin, 2009.) The doctoral studies signify different matters individually and color the lifecourse in a diverse manner. The traditional norms of doctoral studies have broken up, in which case the individual processing and the conscious choices are emphasized. Individuals continuously meet new possibilities and risks without knowing the consequences of their choices (Beck, 1992; McWilliam, 2009). With the individualizing development of lifecourse, what is rather examined are different lifecourses; reflective and narrative biographies (Diewald \& Mayer, 2009).

The doctoral process is reflected in the everyday life and future of the different doctoral students' lifecourse in many and diverse ways. The diversified lifecourse appears as a personal project which consists of areas that are experienced individually as significant, such as the doctoral education, family and different employments. The diversified lifecourse and the expanded possibilities require an examination of matters as a whole (Mayer, 2009) as well as individual timing of different factors in the lifecourse (Macmillan, 2005). The everyday life is the combining of the separate areas, such as of studies, family and work and, at the same time, actions that reach to the future.

\subsection{Doctoral Student in the Changing Contexts}

Global, social and academic changes and the emphasis on individuality become concrete when individuals are examined in different contexts. In the process of change, the wider contexts and lifecourses form an interesting equation in which the individual and public areas are in close interaction. The tightening pace and the increasing demands are reflected in the individuals: they fulfill external expectations and reach for their own independent objectives. Competition, success and lifelong learning are part of the global development and they are manifested in the academic everyday life, also in that of a doctoral student (Ylijoki \& Ursin, 2013).

Often the doctoral students are perceived incorrectly and narrowly as young people aiming for an academic researcher career. However, the doctoral students do not form a uniform group: life situations, motives to graduate with a doctoral degree, career backgrounds and financing channels create individual doctoral students (Ahola, 2007; Baker \& Lattuca, 2010.) In addition to the graduate schools, doctoral studies can be undertaken in addition to working in a university or other work, with the scholarship or in the research project. The young people beginning their career graduate with the doctoral degree in the graduate schools, with a scholarship or in a university in the research and teaching tasks. Older people and those in the working life graduate with the doctoral degree in addition to their work. It would seem an international and increasing practice is to graduate with a doctoral degree directly after a Master of Arts degree and the turn to establish a possible family comes only after laying down the foundation of an academic career (Jacobs \& Winslow, 2010).

When speaking of the doctoral education and the future doctors, the individuality, systemic nature and comprehensiveness of lifecourses and contexts of the micro level are often dismissed. At the individual level the doctoral studies are composed from different starting points to form a functional equation for one's own everyday life, which in itself is an interesting and a valuable skill. The experienced enthusiasm and commitment as well as the balance between the resources and challenges are central in organization and in progressing in the doctoral studies (Pyhältö, Vekkaila, \& Keskinen, 2012). At the same time it is to be noted that the future of an academically highly educated individual appears as open, uncertain and full of new challenges (Ylijoki \& Ursin, 2013; Bitusikova, 2009). The doctoral degree does not guarantee automatic success but the competition, for example, for the work which corresponds to the education increases (Ylijoki, 2010; Rhoades, 2012). Getting into the competition of doctors is an uncertain risk investment in spite of all the developed doctoral schools and paid research work.

Continuously increasing demands are projected for the future doctors. The doctoral degree is not only an educational title or a personal achievement but versatile knowledge and skills to be utilized (Golde, 2005). The majority of the future doctors move to or continue in the employment of other areas of working life and only a fraction of them will continue their career in academic assignments (Boud \& Lee, 2009; Baker \& Lattuca, 2010). The expertise inside the discipline is not enough, wider skills and versatile competences are needed in the working life (Tymon, 2013), whether working in academic or in other work assignments. The future doctors are wanted as creative and productive performers for genuine contexts (Cumming, 2010), which shows the increase in the status of scientific knowledge in the information intensive world (Ylijoki, Marttila, \& Lyytinen, 2012).

From the point of view of the future development it is significant how the individual micro level objectives and the 
wider macro level objectives meet one another. The development at macro level appears as the hectic nature of the lifecourse, as well as the large, overlapping and target-oriented projects. They become concrete in the doctoral students' everyday lives, their studies, work and family. The doctoral students balance in the limited time resources under the pressures of their own and external expectations. Under the pressure of the competition and individuality, the peer-to-peer support has emerged as a significant factor according to the doctoral students' experiences (Littlefield, Taddei, \& Radosh, 2015). In the future the different web-based solutions will increasingly make individual networking possible which for its part may challenge the significance of the traditional physical working conditions (McAlpine \& Mitra, 2015).

\subsection{Temporal Continuity in the Lifecourse of Doctoral Studente}

The doctoral students perceive the wholeness of their micro level lifecourse which overlaps the wider contexts of the macro level from individual and alternative points of view: what factors, with what schedule and in which order the matters are connected in it (e.g. Beddoes \& Pawley, 2015; Baker, 2008). The continuity of the lifecourse is divided into target-oriented and marked off projects: there are family projects, doctoral thesis projects, work projects, building projects and fitness projects, which on one hand increases effectiveness and on the other breaks the comprehensive understanding. However, graduating with a doctoral degree structures a temporal continuum in the lifecourse and longer time span: it has its connections in the past, its place in the present and expectations in the future, even though, in everyday life it often appears as fragmented and proceeds bit by bit.

The doctoral studies require organization of everyday life and time usage so that the aim of graduating with a doctoral degree can be achieved. With other development, the conception of time and the significance of time have also changed (Garhammer, 2002). The controllability, effectiveness and productivity are especially distinctive for the current conception of time. Time has become an individual's own capital and a resource which can be evaluated and of which there is a constant shortage, especially in the contexts of the academic work. The passing of time is regarded as faster and the perception of it as a continuum of past, present and future has become more difficult than previously. (Harvey \& Pentland, 1999.) The atmosphere of planning has widened comprehensively to encompass the management of time usage and projects in the lifecourse: to family, studies and work career. In the fast moving society which values effectiveness, the systematic operation reaching to the future is an expectation. (Couclelis, 2004).

However, the lifecourse does not proceed as scheduled and straight forward but as a sum of the numerous stages, fragments and also the coincidences. Graduating with a doctoral degree is a significant stage requiring a time input in the continuity of the lifecourse (Barnacle \& Mewburn, 2010), and it would be beneficial to at least orientate to its subsequent stages if planning is not possible due to the changing contexts. If doctoral students do not perceive the prevailing trends or know their own direction, they can be faced with unclarity regarding the possibilities and restrictions of the future. (Boud \& Lee, 2009.) At the micro level the processing of the significance of the doctoral studies and the temporality would seem to be central in relation to the changes in the macro level. Still, often the micro level, or the doctoral students and their everyday lives, are in the background and adapting in the studies (Leonard \& Becker, 2009).

\section{Method}

\subsection{The Aims and Conducting the Research}

The temporality of the lifecourse is connected to the narrative construction of past, the present and future. The lifecourse contains breaks and illogicality but it is explained as an understandable and chronologically continuing story. The future does not appear as logical and continuous in the same way but contains the fragmented and the alternative excerpts in the projected outline in the story of lifecourse. (Heidegger, 1996.) Also the female doctoral students with a family analyze their lifecourse in a narrative form. The lifecourse study has become more popular in the global change in which the individuals reflect on themselves and set goals for themselves.

\subsection{Participant Characteristics}

The research material consisted of loosely themed and narrative interviews of 12 under-40-year-old female doctoral students with a family. The examination combines the changes that are met by the society, scientific field and individuals and which connect the macro and micro levels. The starting point is an individual experience from which the phenomenological research tradition proceeds. The individual experience has a context where it takes place, it is interpreted and understood in the spirit of the hermeneutic dialogue. Of the lifecourse experiences a logical, complete and comprehensive intelligible story is interpreted, a form in which the experiences are structured and shared. The 
lifecourse research and narrative are linked in their nature. The narrative construction conveys significant lifecourse experiences, interactively and communally forming the conception of self. (Chase, 2005; Atkinson, 2007.) In the center of the examination are the individually interpreted experiences of the female doctoral student with a family in the temporal continuum of the lifecourse. The stories convey the temporal nature of the lifecourse (Ricoeur, 1988) as well as the cumulative nature of the forming understanding. Interpreting the narrative story of the lifecourse is a journey of exploration to the past and at the same time a glimpse in to the future (Chase, 2005). In order to reach understanding, one needs to know the past and the present and to predict the future (Heidegger, 1996).

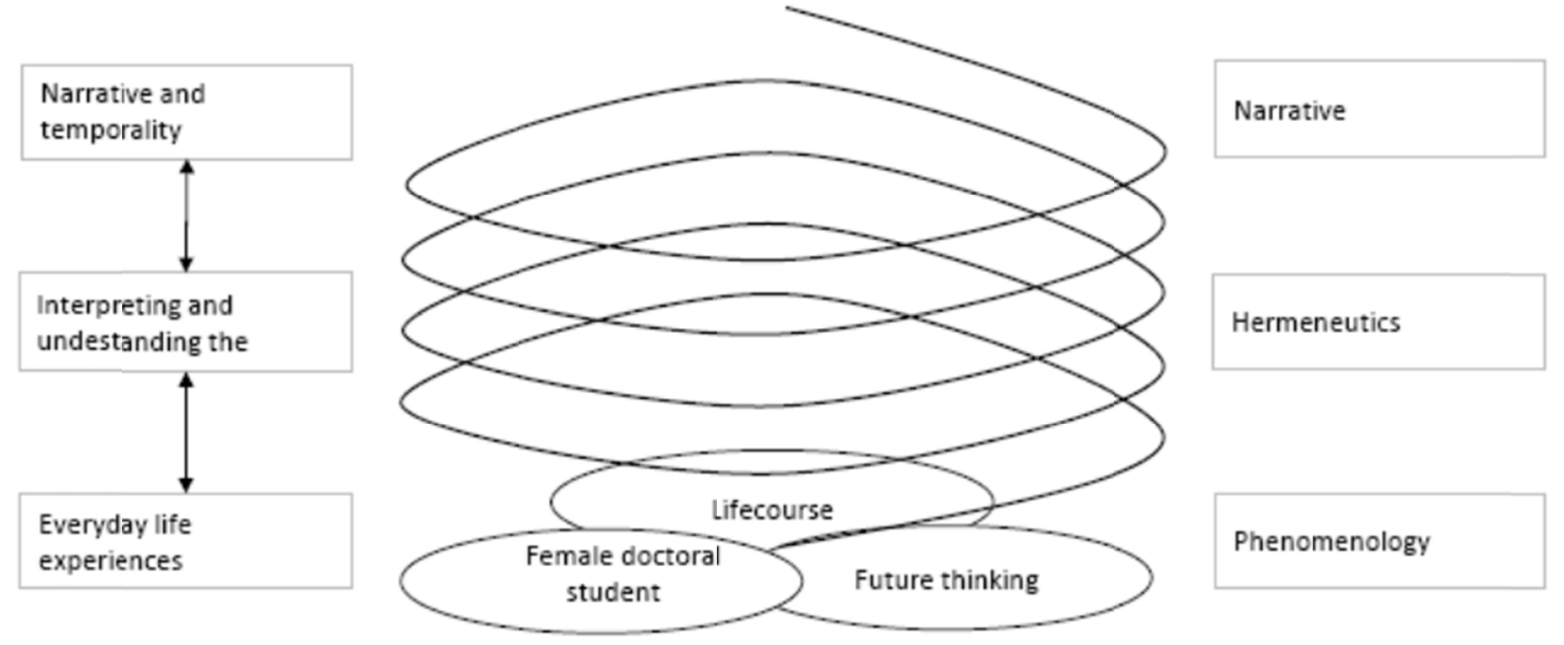

Figure 1. Research Phenomenon and the Multimethod Starting Point

\subsection{Sampling Procedures}

The female doctoral students participating in the research carried out their studies in three different Finnish universities and were at different stages in their studies in different fields. The average age of the female doctoral students was 32. All of the ones participating in the research had begun their doctoral studies in the 2000s. The doctoral studies had lasted under five years at the time of the interview. The Finnish doctoral education system makes the different ways to complete the doctoral thesis possible, with the different schedules and financing. At the time of the research, seven of the women furthered their doctoral studies in the university as paid work and full-time, two studied full-time with the scholarship, one was on family leave, one was unemployed and one studied part-time in addition to other work. All had undertaken their doctoral studies full time at some stage with the help of different financing. Eight of the female doctoral students were married, three in the common-law marriage and one student was a single parent, the number of children varied from one to three, the children's average age was 5 years.

\subsubsection{The Theme Interviews, Stories and Temporality}

The theme interviews were well suited for connecting the temporal continuity, the experiential nature and narrative perspective of the lifecourse. The stories formed and conveyed experiences of the experienced and interpreted reality (also Chase, 2005). The wholeness of the lifecourse is not simple and clear but through processing by themes the interaction, tensions and also the contradictions of different areas were individually brought out (see Atkinson, 2007; Chase, 2005). The lifecourse stories proceeded narratively, temporally and thematically constructing an intelligible wholeness, but simplifying the reality. The narrative is an essential part of the nature of my study subject. The past is understood, the present is analyzed and the future is anticipated by telling the lifecourse story again and again (Ricoeur, 1988; Heidegger, 1996). Along with the description of subjects, give the mended size of the sample and number of individuals meant to be in each condition if separate conditions were used. State whether the achieved sample differed in known ways from the target population. Conclusions and interpretations should not go beyond what the sample would warrant.

\subsubsection{Forming the Types of Narratives}

The analysis of the material was the content analysis of themes which develop hermeneutically as well as narrative classification stemming from the themes and the construction of the types of narratives. With the types of narratives 
and the classification I was searching for the original and comprehensive lifecourse essence for the material, at the same time, the material split into themes was made whole and synthetic. There are a number of methods and objectives of narrative analysis (Polkinghorne, 1995), my aim was the forming of an intelligible story (see Gergen, 1994). Through the thematic and holistic personal analysis the types that have typical qualities and typical lifecourse stories took shape. In the analysis process three types which are organized contentually and narratively were formed: the Project Manager, the Survivor and the Seeker. The classifying was based on the specifying of the roles of the wholeness of lifecourse and of doctoral studies of the female doctoral students.

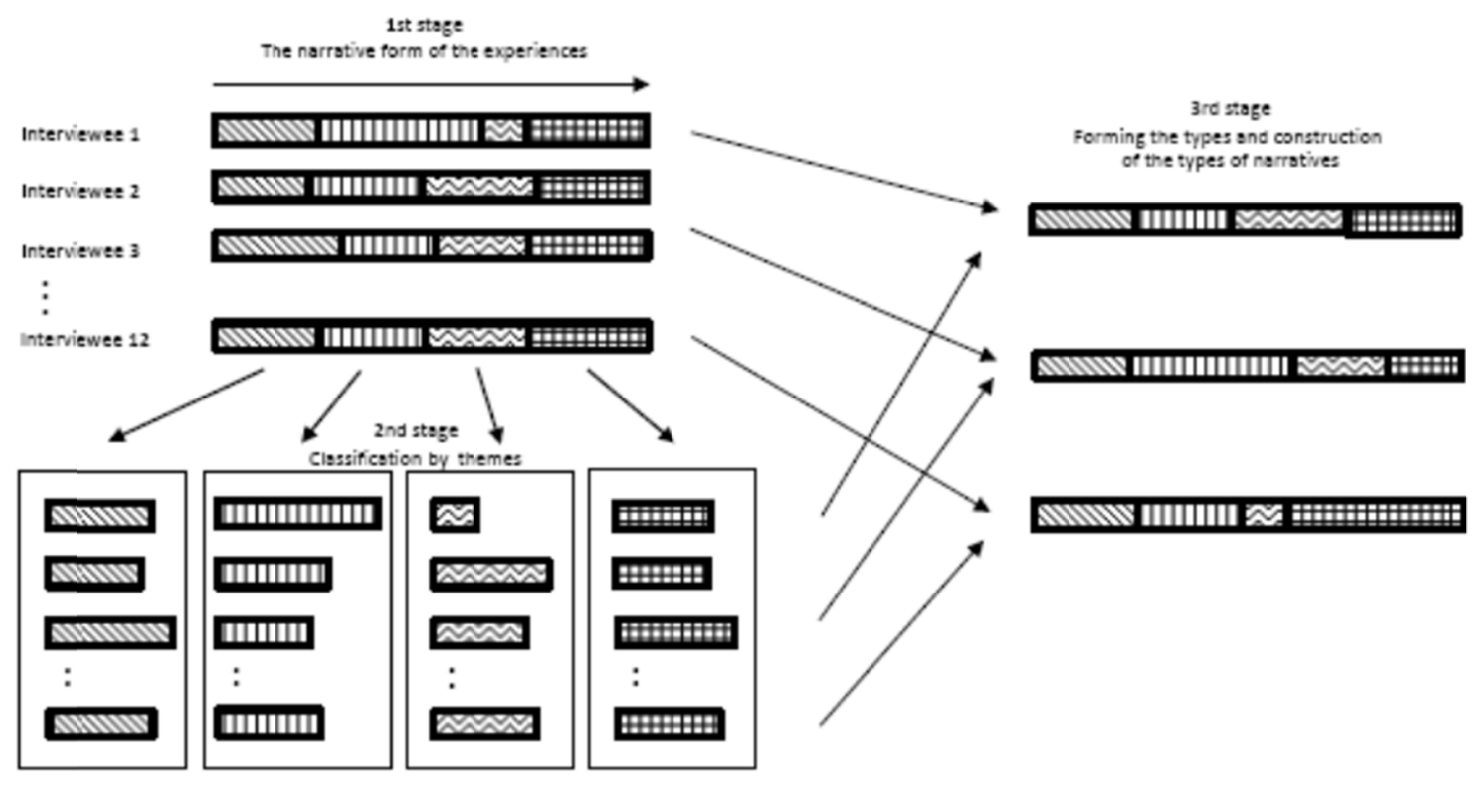

Figure 2. Themed Analysis of Lifecourse Stories As Well As Forming of the Types of Students and the Types of Narratives

The narratives have a plot as well as the beginning, middle and end according to a lifecourse story. Ricoeur (1988) emphasizes the narrative, the logic between the individual events and the wholeness. Classification and narratives made possible the creation of a more uniform and comprehensive understanding of the continuity of a lifecourse of a female doctoral student with a family and they strengthened the narrative point of view which was naturally connected to the phenomenon. The classification reassembled the subject which was divided in thematic examination to the narrative lifecourse form which is characteristic to it. Thus the continuity of a lifecourse and future thinking as well as the comprehensiveness which is larger than the individual themes justifiably appeared. The types of narratives consisted of the same themes among themselves but their stresses of contents, quality and significances varied according to the women's stories. In the forming of the types of students and the types of narratives I emphasized a comprehensive interpretation of the lifecourses, past, present and future in connection with the themes which are central from the point of view of the study.

\section{Results}

\subsection{From the Doctoral Students' Heterogeneous to Differentiated Lifecourses}

The childhood, the childhood family and the early school years of all the female doctoral students were 'quite ordinary' according to the research participants: the parents of the nuclear family had a vocational education, some had academic education and a lot of work which was in accordance with the education was done. The school was comfortable and the success was average. Life was in every way steady and ordinary.

After the early heterogeneous years the lifecourses of the female doctoral students became differentiated and individualized. In the content analysis process of the lifecourse narratives of under 40 -year-old female doctoral students with a family, three types of students and the types of lifecourse narrative were formed: the Project Manager: steady and periodic lifecourse, the Survivor: changeable and flexible lifecourse and the Seeker: in crisis and uncertain lifecourse. 


\subsection{Types of Lifecourse Narratives}

\section{Project Manager: steady and periodic lifecourse}

The Project Managers $(\mathrm{N}=4)$ analyzed their life as a complete wholeness. They acted with commitment (see Martinsuo \& Turkulainen, 2011) but reactively according to their values and plans. The Project Managers did not commit themselves simultaneously to many matters but the sequenced demanding lifecourse matters and reserved enough time for them.

"After the first child, I had a feeling that now I want to finish that thesis and only after that to think about the possibility of having another (child). I didn't want to take on so many things one on top of the other, I have learned that it pays to have fewer matters piled up."

The organizing was facilitated by the doctoral studies undertaken as paid work (also Hakala, 2009), by the versatile support offered by the academic work community (Stubb, 2012) and the experienced meaningfulness. In the beginning of the academic career there were difficulties, through which the Project Managers developed a persistent work attitude, the achievements require an effort. They were aware of their objectives and operated consistently according to them, the career took off and went from strength to strength. The doctoral studies were not obsessive performing but a part of the versatile life.

"Ordinary challenges, when you have a child, to do with time usage at least. At the moment I only work on my thesis during the working hours, in other words 8-16. Then my other time is for the family and the child and especially now when we are building a house, so my husband is on the building site every evening. We both have also coldly cut down our own hobbies. Life is like this now, for this year."

The Project Manager's strength was the time management. There was a place for important matters, such as doctoral studies and family, any other time was used according to the situations. The challenge was the general combining of work and the family in everyday life. The approaching dissertation and the future changes burdened the Project Manager, especially finding steady employment as a doctor worried them. The future doctoral degree appeared as a turning point of the lifecourse.

"I have planned to continue in the research career. At this stage it seems that it would be possible, although the financing channels are quite difficult and narrow. I would have hoped to have had longer contracts than what it looks like. I'm becoming quite a temp worker. Well I don't know, it is kind of negative but also acceptable in a way. At least to begin with."

The core of all the solutions was the welfare and balance of the family. The Project Manager built the future purposefully and challenged their own knowledge and skills courageously. The Project Manager's everyday life was clearly project-like and she herself acted as the manager of projects. In figure 3, the importance of the central areas of the lifecourse, the family, work and studies condense as experienced by the Project Manager in the different dimensions of temporality. In the Project Manager's lifecourse the family is the most important in all the dimensions of temporality, the importance of the work is ascending and more moderate later in the future. The significance of the studies decreases after graduating with a doctoral degree. The general image of the direction of the lifecourse is positive.

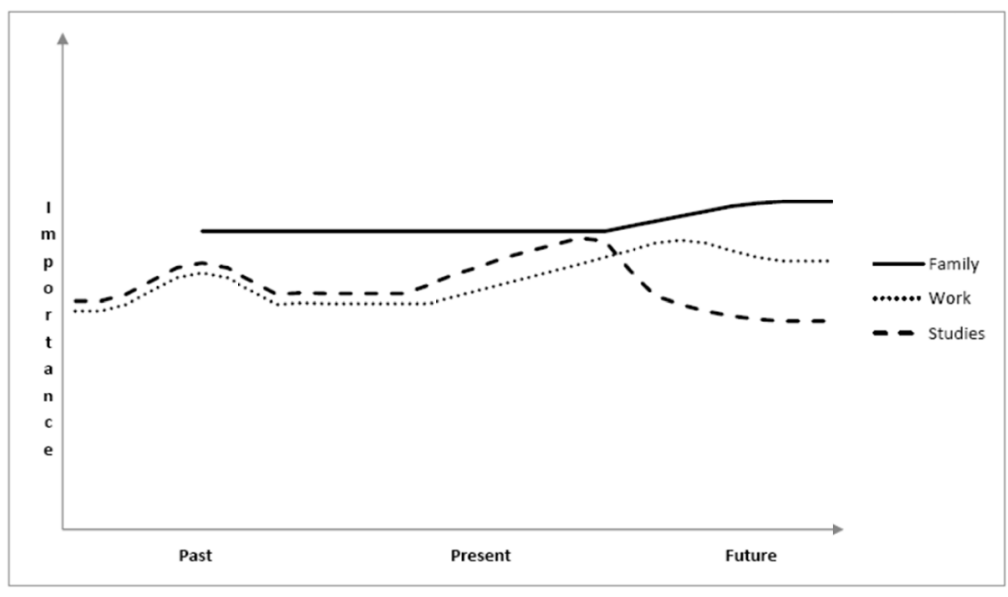

Figure 3. The Construction of the Project Manager's Lifecourse 


\section{Survivor: changeable and flexible lifecourse}

In the Survivor's $(\mathrm{N}=6)$ life there was variability, flexibility and everyday organization. The Survivor's multiform everyday life consisted of reactive organization. The Survivor linked the doctoral studies to the work and overlapped everything into the family life. The Survivor's talk about protecting the home from the work and emphasizing family-centredness was conflicting because the Survivor had several projects running simultaneously. The constant hurry and the divided presence were tiring at times but the Survivor was used to it because the family had been started during the Master of Arts studies and the everyday life of the family with children had its routines.

"I will get a scholarship for a year and I don't know if it is OK if I will stay at home with the children for a month in the summer. It must be, my children need their mother. I try to continue so that I have just the same working days and routines as earlier. I have so much work at home and at work and it is all under control, but any other life, it is not in order, the running matters. It is really difficult."

The Survivor's past, present and future were organizing, anticipating and creating the possibilities for work. The most important and current objective was finding steady employment which may prove to be a turning point in the lifecourse of the Survivor. At times the Survivor could seem passive academically (Dill et al., 2006) but the slow progress of doctoral studies was caused by the hectic nature of other life.

"At first I made different schedules, even quite exact ones, but the baby changed that a little. I have thought, that I would do it as fast as I can, eight hours per day and regularly during five days per week, the maximum of three years. I would want to get it done quickly and go properly to work. How can I manage to wait, to get proper work"

"I read articles a little at home, in the evenings. Sometimes it feels that it's nice to read something when you are busy with the children. There is, of course, the combining of a family and work in everyday life, when you have two children and the hobbies of yourself, your husband's and children's. I should have enough time to fit all of this together. I can't do very long working days, because I really have to go home."

In addition to an actual expertise of contents, the Survivor learned valuable skills, such as organization with the part-time doctoral studies. Students graduating outside the graduate schools, the work-based doctorates, indeed adopted more knowledge for working life than others (Costley \& Lester, 2012). The ethos of lifelong learning as well as the spontaneous activity which is an important factor from the point of view of the doctoral process, are reflected in the Survivor's actions (Lahenius, 2012). There were possibilities and challenges in the Survivor's future, especially the future employment controls the direction of work career and is reflected in the lifecourse.

"I cautiously hope that I would get a project after the thesis research and if possible, I would combine a short bit abroad with it. A maximum of three months, would go there to learn certain things and come back. I wouldn't want to leave for longer than that without the family. Sometimes we joke that we would go to some warm country together. But I do not believe that it would happen for real."

The Survivor may drift to the flexible and temporary academic work force (Hakala, 2009). The development of the different lifecourse sectors in the future can change the direction of the wholeness significantly. In the present, the life of Survivor was hectic and continuous survival. In figure 4, the importance given by the Survivor to the central areas of the lifecourse, the family, work and studies in different dimensions of temporality is presented. The different areas have formed a close wholeness for a long time. The position of the family as the most important area of the lifecourse is solid, the importance of studies decreases towards the future and that of the work is increasing. In the survivor's lifecourse there is strong continuity and overlap for the importance of different sectors. 


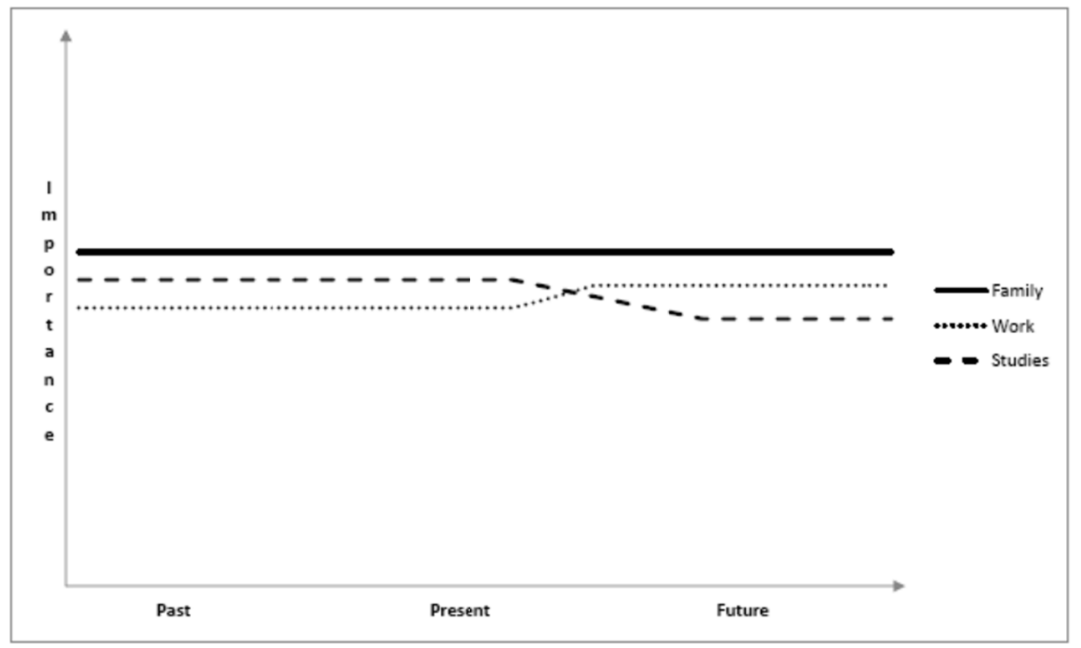

Figure 4. The Construction of the Survivor's Lifecourse

\section{Seeker: in crisis and uncertain lifecourse}

The Seeker's (N=2) academic career began as thought-out, meaningful and successful. However, with the doctoral studies, she avoided unemployment and did not make the conscious decision to commit to the doctoral process (cf. Martinsuo \& Turkulainen, 2011). Starting a family at the first stage of doctoral studies changed life and the adversities accumulated. The seeker was uncertain about her studies, work career and own knowledge. Being part of an academic work community does not protect one from the adversities and from the considerations to discontinue the studies (Stubb, 2012). The uncertainty and the anxiety were reflected in life as a whole.

"When I planned the postgraduate studies I already knew then, that I get stressed about all the irrelevant things. I thought that when I have the child it solves these problems. That when I come home, I forget those work matters and do not worry the unnecessary things and concentrate better on the essential. I feel that it might have worked for a little while, like great, that even if I have a small child I can still make decisions like these in my own life and I was very grateful for it. Now I have become dulled to it and the novelty has worn off, even though the life should be easier now than when I had a small child."

One alternative was discontinuing the doctoral studies which is quite common in the doctoral studies. The American system for doctoral education is considered the best in the world but that also has areas that could be developed: the percentage discontinuing their studies is about 40 percent (Golde, 2005), also in Finland as many as $45 \%$ of the doctoral students consider discontinuing their studies (Stubb, Pyhältö, \& Lonka, 2012). Reasons for discontinuing and considering that option need clarification and more effective doctors' graduation is sought after. One wants to clarify the reasons for discontinuing and considering it and to intensify the doctors' graduation. The ineffectiveness consumes the economical, supervisory and emotional resources of those involved in the doctoral education. (Golde, 2005.) Student's own attitude towards doctoral process and persistence at even in the difficult stages are central according to Stubb (2012). However, the Seeker's context was more demanding and comprehensive than the individual challenging situations.

"I am tired of the work, it also comes home. It feels unbearable, it has a huge effect on making this decision. If I didn't have children, even though now this is really hard, I don't enjoy this one bit, I might find the ambition and would just get this done. Now I cannot live in a way that I'm not happy. It is more important to make a decision which keeps me well in my mind. It can so easily follow me home. It well could be that if I did not have children, there would be time to recuperate sometimes.

The Seeker's lifecourse was at the turning point where the responsibility for the family and its livelihood narrowed the choices of the future. The Seeker's spouse was not in paid work. The Seeker trusted that the lifecourse crisis would ease with the conscious and considered decision-making. The maternity leave of the near future would provide a change to have a break to reflect, make decisions and to rediscover the direction for the lifecourse. Figure 5 reflects the importance of the different areas of the lifecourse as experienced by the Seeker. All the sectors of the lifecourse, family, work and studies were on the descent subsequent to the earlier increase. In a difficult lifecourse situation the family was still the most important and the position of work and studies was on the rise. The lifecourse 
situation with little meaning was comprehensive, however, the expectations for the future appeared more positive.

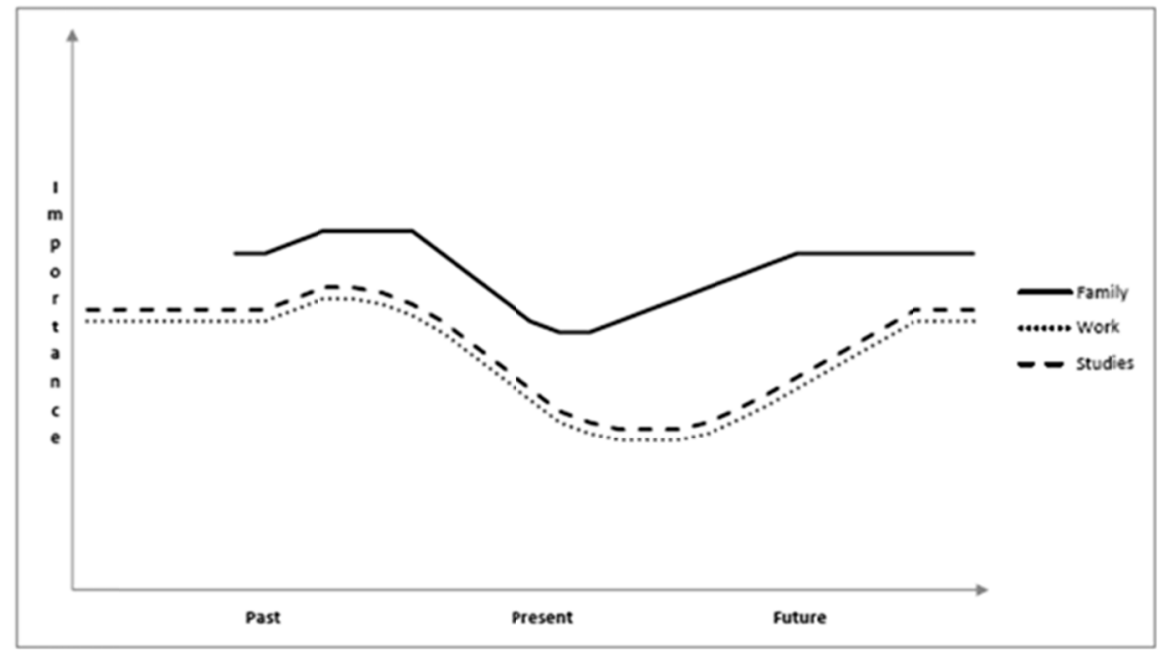

Figure 5. The Construction of the Seeker's Lifecourse

\subsection{Features of the Types of Female Doctoral Student on Temporal Dimensions of the Lifecourse}

The lifecourses of different types of students became differentiated after the childhood and adolescence and the intertwining of lifecourse factors promoted the individuality taking shape. For example, the first stages of the academic career, the time of starting the family in relation to the stage in studies, the form of undertaking the doctoral studies and the stage of doctoral studies at the time of the interview are for their part reflected in the different types. The temporal dimensions of lifecourse with their different factors overlap one another and the events are given new significances as the lifecourse proceeds. In table 1, the qualitative features of the temporal dimensions of the lifecourses of the presented types are summarized.

Table 1. Types of Female Doctoral Students and Typical Qualitative Features of the Temporal Dimensions of the Lifecourse

\begin{tabular}{llll}
\hline $\begin{array}{l}\text { Temporal dimension } \\
\text { lifecourse }\end{array}$ & Project Manager & Survivor & Seeker \\
\hline Past & $\begin{array}{l}\text { laborious, successful happy, ordinary } \\
\text { choices }\end{array}$ & easy, planned, ordinary \\
Present & $\begin{array}{l}\text { schedules, objectives } \\
\text { change, uncertainty, } \\
\text { curiosity, excitement }\end{array}$ & $\begin{array}{l}\text { Everyday life, busy, varied } \\
\text { Future }\end{array}$ & $\begin{array}{l}\text { crisis-like wholeness } \\
\text { open, frightening }\end{array}$ \\
\hline
\end{tabular}

\subsection{Comparing the Types: The Turning Points and Continuums of Lifecourses}

The turning points in the types of lifecourse narratives of the different types of students were placed and defined variably. In the Project Manager's lifecourse the radical stage was connected to the admittance to studies and university which was not a matter of course. The struggles for a meaningful study career strengthened the Project Manager's aim orientation which benefited in the building of the academic career. In the Survivor's life expense it is challenging to name the clear turning point. One turning point was starting the family during the Master of Arts studies in which case the Survivor adopted the connecting of different contents in life. Having a family and the versatility strongly stamped the lifecourse stages of the Survivor. The turning point of the Survivor's lifecourse may be placed in the future in the form of successful employment. Two big life changes were placed in the turning point of the Seeker's lifecourse: beginning the doctoral studies and starting a family. The life changed, becoming demanding toil and the direction of the future uncertain.

In addition to the turning points of the lifecourse of the different types, each type proceeded steadily in their lifecourse and, at least when constructed afterwards, the lifecourse appeared continuously organized which at the same time emphasizes the differences between the types on the basis of the presented factors. The continuum of the Project Manager's lifecourse was steadily anticipated and built to alternate consciously. The completion of doctoral 
studies and the employment to follow determined the near future. Furthermore, she hoped for another child. When examining the future, the most significant factor in the project Manager's lifecourse was the future employment which seemed fairly stable due to the significant earlier work experience. The beginning of the work career following the graduation with the doctoral degree may however consist of short term work assignments which also could be fragmented by the hoped-for family leave.

The Survivor's lifecourse was varyingly multi-levelled and functional. In the lifecourse, a flexible and everyday organization was emphasized, in which case the building of the future also got partly blurred. At the same time, the strong organizational skills were major capital for the Survivor. The Survivor's everyday family life was packed and busy but rewarding and permanent along its major lines. The Survivor lived strongly in everyday life, she did not postpone matters. The Survivor actively searched for her own place, especially in the working life. Meaningful employment and family were more important than graduating with a doctoral degree.

In the Seeker's lifecourse thinking, being in crisis and the present state of being in cross-roads were emphasized. The past was successful and clear, the present was in the crisis and the future stages were uncertain. If she finds the meaningfulness and sufficient self-confidence in the doctoral studies, the studies and the academic career may proceed favorably. In the seeker's near future there was a wish for an addition to the family which would make the separation from the unsatisfying spiral possible. Also the spouse's employment would have significance, it would lighten the economic responsibility of the Seeker and would make a genuine choice possible. Also continuing to the studies in another area can be a successful solution. It was positive in the Seeker's difficult situation that she realized the need for change.

\subsection{The Significance of the Contexts}

The academic contexts are in a significant position for doctoral students irrespective of starting points and objectives, and the different types of students were placed and operated in them in different ways. The Project Manager had reached a fairly good position in the university because of her doctoral studies undertaken as work even though she was still in the precariat. The position on the fringe is a bearable one when one interprets it as the norm (Nikunen, 2012). The Project Manager adopted the academic practices and the competitive position was good but nothing was certain. Often the position at the fringes of the academic field is negatively experienced but the possibilities of moving away from there are limited: to struggle or to resist (Nikunen, 2012). Also the Seeker attached to the academic context but it did not adapt to a competitive situation and rebelled against it. She was about to choose another, more meaningful career. Usually rebelling is not considered as a solution even though the system is criticized (Nikunen, 2012). The doctoral studies are in many ways a balancing act after which the academic work further requires good tolerance for stress (Hakala, 2009). The Survivor placed herself in the margins for the work and studies and struggled in order to get a share in them.

Employment after graduating as a doctor and also before it worried all the types. The closer the graduation was, the more the employment was thought about, which was evident especially for the Project Manager. Traditionally, high education has reduced the risk of unemployment but the global economic recession and the growing numbers of unemployed increased the worry for the women in the study. They told that they had struggled with low income and in uncertain fixed term employment for so long that it was expected that the high education and the expert knowledge could be used productively, making possible the more permanent employment and a proper salary. Of course, they also had the economic responsibility in supporting their family. The education, work and money were indications of capability and independence above all to the graduating women themselves.

In the future the doctors will work to an increasing extent outside the academic context, this is indeed what the female doctoral students in my study had partly prepared for when exploring the wider employment opportunities. The graduating doctors experienced as a challenge that their own expertise and the demands of the working life do not meet. Often it is forgotten how different skills and expertise the doctors who have participated in different contexts have acquired. Stereotypical images narrow a genuine dialogue between the doctors, doctoral education and working life. The different doctors have different contexts where different expertise and different competences are based. Doctoral education does not produce one ready profession or indicate a clear career path, but they form individually as a sum of different factors. The doctoral students perceive the doctoral process through the growth in their own progress and understanding, the hermeneutic process takes time.

\subsection{Types of Students and the Significant Factors of Lifecourse}

All the female doctoral students had got used to the changing conditions in their everyday life and told that they longed for stability at times. The uncertainty which was connected to the work of the future of all the types was 
balanced by the family, furthermore, it was experienced that the family increased the feeling of continuity of the lifecourse. The family was an anchoring factor in the future - one wanted to reserve more and more time for the family. Irrespective of the type of student, the future was also otherwise structured from the point of view of the family. The family was not an obstacle in realizing the other sectors of the lifecourse but a central and concrete balancing factor.

In the types and types of narratives the lifecourse structure of a female doctoral student with a family is reflected as a wide entity. In an individual lifecourse, varying significances are given to different factors. No route is easy in advance, the most suitable choices must be made to fit to one's own individual situation and one must act both reactively and proactively. It indeed is central to realize one's own starting points, objectives and conditions. The continuously changing contexts require a flexible attitude. Hakala (2009) thinks that an academic identity is formed from both the traditional and new dimensions. Competition, economic responsibility and uncertainty are the new dimensions. The future doctors graduate in the shade of an uncertain future, they are traveling to an uncertain and changing world in the winds of which the family creates stability.

Rating the types of students is neither sensible nor possible from the point of view of organizing the lifecourse or from the point of view of the successful future because the conditions and all the factors are not under one's own control. However, every one has partial chances of editing a meaningful lifecourse or at least being aware of the different possibilities. By examining the dialogue between the formation of the social factors of the macro level and the types of the micro level, the continuity and change of lifecourse and temporality can be understood. The conception of different doctoral students and their doctoral processes is strengthened through the different types and types of narratives. The aim to understand the types from the individual starting points in the changing contexts is meaningful.

There was continuity but also turning points in the lifecourses of the types of female doctoral students. The beginning of the academic career and the formation of everyday life, the beginning of doctoral studies, starting a family, graduating with a doctoral degree and finding employment formed the turning points. The turning points changed or would change the direction of the lifecourse. The beginning of the academic career established a fairly constant norm of the academic everyday life. Starting a family was a lifecourse turning point which also represented the continuity for all the types. As the turning point of the future, graduating as a doctor, employment and decision on the follow-up of doctoral studies were anticipated. In the future of the types of students, the employment and the adoption of the expert identity can prove to be a turning point and a factor which affects the direction of the lifecourse. While the studies were uncompleted, the uncertainty regarding work structured future thinking significantly.

What kind of insights can then be made with the help of changing and global contexts from the different types and individual stories of the female doctoral students? It is clear that the doctoral students and the future doctors are individual in many ways. The individual backgrounds, the accumulating knowledge and experiences as well as the everyday contexts form different future expectations and future possibilities. The doctors' individuality is in many different ways reflected in the doctoral education and also in working life. The doctoral students from different backgrounds set different expectations for the education, for example, the doctoral student coming from the working life challenges the academic context differently compared with a young doctoral student. The graduating doctors' knowledge and expertise are built from different starting points, in different contexts and colored by the individual objectives - one can indeed talk justifiably about the differentiating doctors of the future. At the same time, the supervision of doctoral studies is also facing new challenges: how are the supervisors connected to academic and traditional contexts able to step into the positions of the doctoral students who come from different starting points, to identify with the new doctors' competitive culture and to guide them to the different possibilities of the future?

\section{Discussion}

The three lifecourse types of female doctoral students and the types of narrative that have been presented above were based on natural ways to structure the lifecourse in the long and short term. The freedom brought by the individualizing development and, at the same time, the pressure of the competitive culture are met in the doctoral studies and eventually after them as the experts, as individuals. The future doctors do not have a ready career path or the clear right choices but every one weighs their own starting points, their everyday restrictions and their possibilities of the future personally and from their own contexts. The self-awareness of the new doctors and agency are emphasized in the temporal continuum of the lifecourse and comprehensively in all the areas of the lifecourse. Indeed it would seem beneficial to practise a systematic and aware but still a reactive way of life. 
A more comprehensive approach is needed in the doctoral education. The doctoral education is between the old and the new time (also Cumming, 2010). The traditional academic doctoral education is becoming knowledge-based and strengthening the new models of thinking and operation. At the same time, the creative component of doctoral thesis work is emphasized, exact external control or binding it to the time and place is not suitable for it. The flexible individual orientation of doctoral studies shows the importance of continuous learning and individual knowledge, the doctoral studies are not just the matter of completing the degree. (Pearson, Cumming, Evans, Macauley, \& Ryland, 2011). The direct economic advantage thinking which is directed at the doctors also indicates the restricted idea of the doctoral studies and at the same time narrows the different dimensions of the doctoral process. The clearly seen advantages and benefits of doctoral studies are multi-levelled, they cannot be unambiguously proven (Halse \& Mowbray, 2011).

In the high-quality doctoral process the starting points of the individual doctoral students are recognized, the process is carefully planned and attention is paid to high objectives set for the doctoral education (Golde, 2005). The doctoral students already have expertise and networks which can be strengthened in the doctoral education, even though the naturally accumulated capital and its individual dimensions cannot be absolutely presented (Bansel, 2011). The doctoral education indeed needs to pay stronger attention to the individuality, to the realization of the different starting points and objectives and to the transparency of the whole process. The university is a part of the system and it has an important interactive task as a developer of the individuals and communities and as an educator with its partners. The doctoral students' experiences are at their best the starting force of reforms.

\section{References}

Ahola, S. (2007). Doctoral education in Finland: between traditionalism and modernity. In S. Powell, \& H. Green (Eds.), The doctorate worldwide (pp. 29-39). Buckingham: Open university Press.

Atkinson, R. (2007). The life story interview as a bridge in narrative inquiry. In D.J. Clandinin (Eds.), Handbook of narrative inquiry (pp. 224-245). Mapping a Methodology. California: Sage.

Baker, J. (2008). The ideology of choice. Overstating progress and hiding injustice in the lives of young women: Findings from a study in North Queensland, Australia. Women's Studies International Forum, 31, 53-64. http://dx.doi.org/10.1016/j.wsif.2007.11.001

Baker, V., \& Lattuca, L. (2010). Developmental networks and learning: towards an interdisciplinary perspective on identity development during doctoral study. Studies in Higher Education, 35(7), 807-827. http://dx.doi.org/10.1080/03075070903501887.

Bansel, P. (2011). Becoming academic: a reflection on doctoral candidacy. Studies in Higher Education, 36(5), 543-556. http://dx.doi.org/10.1080/03075079.2011.594592

Barnacle, R., \& Mewburn, I. (2010). Learning networks and the journey of becoming doctor. Studies in Higher Education, 35(4), 433-444. http://dx.doi.org/10.1080/03075070903131214

Beck, U., \& Beck-Gernsheim, E. (2002). Individualization: Institutionalized Individualism and Its Social and Political Consequences. London: Sage Publications.

Beck, U. (1992). Risk society. Towards a new modernity. Transl. Mark Ritter. London: Sage.

Beddoes, K., \& Pawley, A. (2015). 'Different people have different priorities': work-family balance, gender, and the discourse of choice. Studies in Higher Education, 39(9), 1573-1585.

Bitusikova, A. (2009). New challenges in doctoral education in Europe. In D. Boud, \& A. Lee (Eds.), Changing practices of doctoral education (pp. 200-210). London: Routledge.

Boud, D., \& Lee, A. (2009). Introduction. In D. Boud, \& A. Lee (Eds.), Changing practices of doctoral education (pp. 1-9). London: Routledge.

Chase, S. E. (2005). Narrative Inquiry: Multiple lenses, approaches, voices. In N. K. Denzin, \& Y. S. Lincoln (Eds.), The Sage Handbook of Qualitative Research. $3^{\text {rd }}$ ed (pp. 651-680). Thousand Oaks: Sage Publications.

Costley, C., \& Lester, S. (2012). Work-based doctorates: professional extension at the highest levels. Studies in Higher Education, 37(3), 257-269. http://dx.doi.org/10.1080/03075079.2010.503344

Couclelis, H. (2004). Pizza over the Internet - E-commerce, the fragmentation of activity and tyranny of the region. Entrepreneurship and Regional Development, 16(1), 41-54. http://dx.doi.org/10.1080/0898562042000205027 
Cumming, J. (2010). Doctoral enterprise: a holistic conception of evolving practices and arrangements. Studies in Higher Education, 35(1), 25-39. http://dx.doi.org/10.1080/03075070902825899

Diewald, M., \& Mayer, K. U. (2009). The sociology of the life course and life span psychology: integrated paradigm or complementing pathways? Advances in Life Course Research, 14(1-2), 5-14. http://dx.doi.org/10.1016/j.alcr.2009.03.001

Dill, D., Mitra, S., Jensen, H., Lehtinen, E., Mäkelä, T., Parpala, A., Pohjola, H., Ritter, M., \& Saari, S. (2006). PhD Training and the knowledge based society: An evaluation of doctoral education in Finland. Finnish Higher Education Evaluation Council. International Postgraduate Students Mirror 2006. Högskolverket report 2006: 29 R.

Garhammer, M. (2002). Pace of life and enjoyment of life. Journal of Happiness Studies, 3(3), 217-256. http://dx.doi.org/10.1023/A:1020676100938

Gergen, K. (1994). Realities and relationships: soundings in social construction. Cambridge (Mass.): Harvard University Press.

Golde, C. (2005). The role of the department and discipline in doctoral student attrition: Lessons from four departments. Journal of Higher Education, 76(6), 669-700. http://dx.doi.org/10.1353/jhe.2005.0039

Hakala, J. (2009). The future of the academic calling? Junior researchers in the entrepreneurial university. Higher Education, 57(2), 173-190. http://dx.doi.org/10.1007/s10734-008-9140-6

Halse, C., \& Mowbray, S. (2011). The impact of the doctorate. Studies in Higher Education, 36(5), 513-525. http://dx.doi.org/10.1080/03075079.2011.594590

Harvey, A., \& Pentland, W. (1999). Time Use Research. In W. Pentland, \& A. Harvey (Eds.), Time Use Methodology in the Social Sciences (pp. 3-18). New York: Kluwer Academic/Plenum Publishers.

Heidegger, M. (1996). Being and Time. Original: Sein und Zeit (1953). Transl. J. Stambaugh. Albany, New York: State University of New York.

Jacobs, J., \& Winslow, S. (2004). The academic life course, time pressures and gender inequality. Community, Work \& Family, 7(2), 143-161. http://dx.doi.org/10.1080/1366880042000245443

Lahenius, K. (2012). Communities of practice supporting doctoral studies. The International Journal of Management Education, 10, 29-38. http://dx.doi.org/10.1016/j.ijme.2012.02.003

Leonard, D., \& Becker, R. (2009). Enhancing the doctoral experience at the local level. In D. Boud, \& A. Lee (Eds.), Changing practices of doctoral education (pp. 71-86). London: Routledge.

Levinson, D. (1996). The seasons of a woman's life. New York: Ballantine.

Levinson, D. J. et al. (1978). The seasons of a man's life. New York: Ballantine.

Littlefield, C., Taddei, L., \& Radosh, M., (2015). Organic Collaborative Teams: The Role of Collaboration and Peer to Peer Support for Part-Time Doctoral Completion. International Journal of Doctoral Studies, 10, 129-142. http://ijds.org/Volume10/IJDSv10p129-142Littlefield0790.pdf

Macmillan, R. (2005). The structure of the life course: classic issues and current controversies. Advances in Life Course Research, 9, 3-24. http://dx.doi.org/10.1016/S1040-2608(04)09001-X

Martinsuo, M., \& Turkulainen, V. (2011). Personal commitment, support and progress in doctoral studies. Studies in Higher Education, 36(1), 103-120. http://dx.doi.org/10.1080/03075070903469598

May, V. (2011). Why a Sociology of Personal Life? In V. May (Eds.), Sosiology of Personal Life (pp. 168-172). New York: Palvgrave Macmillan.

Mayer, K. U. (2009). New directions in life course research. Annual Review of Sociology, 35, 413-433. http://dx.doi.org/10.1146/annurev.soc.34.040507.134619

McAlpine, L., \& Mitra, M. (2015). Becoming a Scientist: PhD Workplaces and Other Sites of Learning. $\begin{array}{llllll}\text { International of Journal Doctoral } & \text { Studies, } & 10, & 111-128 .\end{array}$ http://ijds.org/Volume10/IJDSv10p111-128McAlpine0768.pdf

McAlpine, L., \& Norton, J. (2006). Reframing our approach to doctoral programs: an integrative framework for action and research. Higher Education Research \& Development, 25(1), 3-17. http://dx.doi.org/10.1080/07294360500453012 
McWilliam, E. (2009). Doctoral education in risky times. In D. Boud, \& A. Lee (Eds.), Changing practices of doctoral education (pp. 189-199). London: Routledge.

Nikunen, M. (2012). Precarious work at the "entrepreneurial" university: adaptation versus "abandon ship". Individualization and identity work: coping with the "entrepreneurial" university. In S. Ahola, \&. D. M. Hoffman (Eds.), Higher education research in Finland. Emerging structures and contemporary issues. (pp. 271-289). Jyväskylä: University of Jyväskylä, Finnish Institute for Educational Research.

Pearson, M., Cumming, J., Evans, T., Macauley, P., \& Ryland, K. (2011). How shall we know them? Capturing the diversity of difference in Australian doctoral candidates and their experiences. Studies in Higher Education, 36(5), 527-542. http://dx.doi.org/10.1080/03075079.2011.594591

Polkinghorne, D. (1995). Narrative configuration in qualitative analysis. In J. Hatch, \& R. Wisniewski (Eds.), Life history and narrative (pp. 5-23). London: Falmer.

Pyhältö, K., Vekkaila, J., \& Keskinen, J. (2012). Exploring the Fit between Doctoral Students' and Supervisors' Perceptions of Resources and Challenges vis-á-vis the Doctoral Journey. International Journal of Doctoral Studies, 7, 395-414. http://ijds.org/Volume7/IJDSv7p395-414Pyhalto383.pdf

Rhoades, G. (2012). Envisioning invisible workforce: Enhancing intellectual capital. In G. Gordon, \& C. Whitchurch (Eds.), Academic and professional identities in higher education (pp. 35-53). New York, Routledge.

Ricoeur, P. (1988). Time and Narrative. Transl. K. Blamey and D. Pellauer. Chicago: University of Chicago Press.

Stubb, J. (2012). Becoming a scholar: the dynamic interaction between the doctoral student and the scholarly community. Dissertation. University of Helsinki.

Stubb, J., Pyhältö, K., \& Lonka, K. (2014). Conceptions of research: the doctoral student experience in three domains. Studies in Higher Education, 39(2), 1-14. http://dx.doi.org/10.1080/03075079.2011.651449

Tammelin, M. (2009). Working time and family time: experiences of the work and family interface among dual-earning couples in Finland. University of Jyvaskyla, dissertation.

Tymon, A. (2013). The student perspective on employability. Studies in Higher Education, 38(6), 841-856. http://dx.doi.org/10.1080/03075079.2011.604408

Ylijoki, O.-H. (2010). Future orientations in episodic labour: Short-term academics as a case in point. Time \& Society, 19(3), 365-386. http://dx.doi.org/10.1177/0961463X10356220

Ylijoki, O.-H., \& Ursin, J. (2013). The construction of academic identity in the changes of Finnish higher education. Studies in Higher Education, 38(8), 1135-1149. http://dx.doi.org/10.1080/03075079.2013.833036

Ylijoki, O.-H., Marttila, L., \& Lyytinen, A. (2012). The role of basic research at the entrepreneurial university: back to basics? In S. Ahola, \& D. M. Hoffman (Eds.), Higher education research in Finland. Emerging structures and contemporary issues. (pp. 111-130). Jyväskylä: University of Jyväskylä, Finnish Institute for Educational Research. 